\title{
What Affects Dewatering Performance of High Density Slurry?
}

\author{
Yunhui Li ${ }^{1, *}$, Heather Kaminsky ${ }^{1}$ D, Xue Yuki Gong ${ }^{1}$, Yijia Simon Sun ${ }^{1}$, Mohammed Ghuzi ${ }^{1}$ and \\ Ardalan Sadighian ${ }^{2}$
}

1 Centre for Oil Sands Sustainability, Northern Alberta Institute of Technology, Edmonton, AB T6G 2R1, Canada; HKAMINSKY@nait.ca (H.K.); YUKIG@nait.ca (X.Y.G.); SSUN@nait.ca (Y.S.S.); MOHAMMEDG@nait.ca (M.G.)

2 Suncor Energy Inc., Calgary, AB T2P 3E3, Canada; asadighian@suncor.com

* Correspondence: yunhuil@nait.ca; Tel.: +1-780-471-8588

check for updates

Citation: Li, Y.; Kaminsky, H.; Gong, X.Y.; Sun, Y.S.; Ghuzi, M.; Sadighian, A. What Affects Dewatering Performance of High Density Slurry? Minerals 2021, 11, 761. https://doi.org/10.3390/ $\min 11070761$

Academic Editor: Pedro G. Toledo

Received: 20 June 2021

Accepted: 13 July 2021

Published: 14 July 2021

Publisher's Note: MDPI stays neutral with regard to jurisdictional claims in published maps and institutional affiliations.

Copyright: (c) 2021 by the authors. Licensee MDPI, Basel, Switzerland. This article is an open access article distributed under the terms and conditions of the Creative Commons Attribution (CC BY) license (https:// creativecommons.org/licenses/by/ $4.0 /)$.

\begin{abstract}
The dewatering of flocculated high density slurry presents a significant challenge to most mining industries. The new technologies to treat high density slurry require a consistent and robust flocculation method in order to enter the market of tailings management. The flocculation of high density slurry, however, due to its complexity, is always a challenge to be undertaken appropriately and to evaluate the dewatering performance correctly. This paper probes the complexity by using a torque-controlled mixing technique to demonstrate the influence of feed properties, polymer type, polymer dosage, and mixing conditions on dewatering performance. The study shows that flocculant should be dosed at the optimal range to achieve the highest dewatering performance. A full dosage responsive curve including under dosage, optimal dosage, and overdosage is critical to evaluate the dewatering performance of high density slurries and flocculants. The mixing conditions such as mixing speed, mixing time, and geometry of the mixing impeller affect the flocculation efficacy. It was found that the dewatering performance of high density slurry is sensitive to solids content, water chemistry, and clay activity. High sodicity and high clay activity in the high density slurry decreases the dewatering performance. Therefore, it is critical to evaluate flocculants across multiple feeds and dosages with replication in order to select optimal dewatering performance. Using multiple key performance indicators (KPIs) to build technical and economic criteria is also critical for polymer evaluation.
\end{abstract}

Keywords: tailings dewatering; fluid fine tailings; high density slurry; flocculation

\section{Introduction}

Most mining industries produce very large volumes of byproduct called tailings such as flotation tailings from bitumen extraction, which are usually in high density slurry form. High density slurries are defined as the slurries where the solids are uniformly distributed in the slurry and do not form a vertical concentration gradient [1,2]. A major environmental and technical challenge to the disposal or reuse of the components of these high density slurries are the efficient separation of fine particles from water. Dewatering the high density slurries, for recycling the release water and reducing the tailings storage footprint, is usually slow and incomplete [3]. The typical solution for this has been dilution prior to flocculation $[4,5]$. However, research in oil sands has shown that it can be challenging to recover more than the dilution water, especially for clay dominated slurries [6]. For example, Suncor found that the amount of water release decreased from $20 \%$ to $12 \%$ in $20 \mathrm{~min}$ when the mature fine tailings were diluted from $40 \%$ of solids to $20 \%$ of solids [6]. Advances at Suncor Energy Inc. in high density flocculation have been able to dewater tailings to a greater extent than previously assumed, but significant care and attention must be paid to the treatment used, both from a chemistry and a mixing perspective [6]. The primary set of challenges to market entry for new high density slurry treatment reagents is a consistent and robust method obtained at a meaningful scale of testing. 
Most dewatering reagents are high molecular weight flocculants, which induce agglomeration of fine particles and solid-liquid separation by binding the particles and enhancing floc strength [7]. Flocculation is a multistep process, normally carried out under conditions that are constantly varying. In general, the flocculation process using a high molecular weight flocculant involves three principal steps: (1) flocculant dispersion in the high density slurry by agitation; (2) floc formation and growth through binding the flocculant on the suspended particles; and (3) floc breakage due to shear, turbulence, etc. [7]. Accurate control of any flocculation process is known to depend upon key parameters such as properties of the high-density slurry, type of flocculant, flocculant chemistry, flocculant dosage, flocculant injection conditions, and mixing conditions employed during the flocculation (Table 1). Mixing conditions are often not sufficiently understood but are absolutely critical in these processes with multiple reaction steps (attachment, growth, and breakage) and where diffusion/concentration of a reagent is important. Bourne provides an excellent summation of the different factors to consider in mixing and selectivity of chemical reactions which all apply in the flocculation of high-density slurries [8]. Given this importance it is critical that the screening tests account for the type of mixing that will be experienced in the field, at least in general terms.

Table 1. Key parameters affecting the high density slurry dewatering performance.

\begin{tabular}{|c|c|c|}
\hline Parameter & Representative Lab Variables & Field Reality \\
\hline $\begin{array}{l}\text { Type of high } \\
\text { density slurry }\end{array}$ & $\begin{array}{l}\text { Solids } \% \text {, bitumen } \% \text {, sand content, } \\
\text { MBI }^{\mathrm{a}} \text {, and water chemistry }\end{array}$ & $\begin{array}{l}\text { Only density can be measured. All } \\
\text { other elements vary without } \\
\text { control. }\end{array}$ \\
\hline Type of flocculant & $\begin{array}{l}\text { Molecular weight, charge, and } \\
\text { structure }\end{array}$ & $\begin{array}{c}\text { Controlled variable, though degree } \\
\text { of hydration may vary. }\end{array}$ \\
\hline $\begin{array}{l}\text { Dosage of } \\
\text { flocculant }\end{array}$ & $\begin{array}{l}\text { Continuum from underdose to } \\
\text { overdose }\end{array}$ & $\begin{array}{l}\text { Since optimum dosage is } \\
\text { determined by the widely varied } \\
\text { feed properties, this is not easily } \\
\text { controllable in the field. }\end{array}$ \\
\hline Premix & $\begin{array}{l}\text { Energy into the high density slurry } \\
\text { before flocculation: mixing speed } \\
\text { and time }\end{array}$ & $\begin{array}{c}\text { Function of } \mathrm{FFT}^{\mathrm{b}} \text { flow rate and } \\
\text { pipeline length. }\end{array}$ \\
\hline Flocculant injection & $\begin{array}{l}\text { Rate of injection, location of } \\
\text { injection, and mixing speed of high } \\
\text { density slurry during injection (i.e., } \\
\text { Relative energy of flocculant to high } \\
\text { density slurry at injector) }\end{array}$ & $\begin{array}{l}\text { Function of FFT flow rate, polymer } \\
\text { flow rate, and injector design. }\end{array}$ \\
\hline Mixing & Mixing speed and time & $\begin{array}{l}\text { Function of flow rate \& transport } \\
\text { distance. }\end{array}$ \\
\hline Geometry of mixer & $\begin{array}{l}\text { Geometry of mixing blade and } \\
\text { mixing beaker }\end{array}$ & $\begin{array}{c}\text { Function of mixing vessel/pipeline } \\
\text { length used. }\end{array}$ \\
\hline
\end{tabular}

Note: $\mathrm{MBI}^{\mathrm{a}}$ : methylene blue index; $\mathrm{FFT}^{\mathrm{b}}$ : fluid fine tailings.

Laboratory small scale dewatering tests are critical for industry reagent selection to treat the high-density slurry wastes prior to the field trials [9]. This is because large scale trials require long duration and high costs to obtain reliable data; meanwhile, small scale trials are cost- and time-effective for application development and optimization, particularly for initial reagent selection. This present work highlights the key factors affecting the dewatering performance of high density slurries treated with commercial flocculants used in the oil sands industry. The high density slurry samples in this study are fluid fine tailings (FFT) which are the wastes from the oil sands extraction in Northern Alberta, Canada. FFT is defined as a liquid suspension of fines in water, with a solid content greater than $2 \%$, but less than the solids content corresponding to the liquid limit [3]. Another byproduct of oil sands extraction, known as oil sands process water (OSPW), was 
used to prepare the flocculant solutions and diluted FFT in this study. OSPW is a complex mixture of dissolved inorganic and organic compounds [3]. The anionic polyacrylamide flocculant A3338, which is commercially available and widely used in the oil sands tailings treatment by both industries and researchers, is chosen for the rapid dewatering of FFT samples in this study. This work describes the repeatable and reproducible flocculation method used for laboratory small scale dewatering studies. Using this method, this study reveals the impact of the mixing conditions, FFT feed parameters, and flocculants dosages and properties on the dewatering performance and robustness of high density slurry. In addition, a currently used flocculant (NRG1000) by one of the oil sands industries along with the polymer A3338 are studied as examples for the polymer evaluation on the high density slurry dewatering.

\section{Materials and Methods}

\subsection{Materials}

Four types of FFT (FFT-1, FFT-2, FFT-3, and FFT-4) from oil sands tailings ponds were characterized by Dean and Stark (D\&S) for bitumen, solids, and water contents [10], methylene blue index (MBI) to indicate the clay activity of a sample [11], wet sieving for fines content [12], density, pH, electronic conductivity (EC), major cations and anions by ion chromatography (IC), sodium adsorption ratio (SAR) salinity, and alkalinity (Tables 2 and 3). Methylene blue index is an index test that measures how much methylene blue dye can be adsorbed on the clay surfaces of a sample by a titration test [11]. Because methylene blue has a strong affinity to clay surfaces and hence displaces any other ion on the clay surfaces, the methylene blue index is used to describe the clay content and activity [11]. FFT- 3 and FFT-4 were diluted using the OSPW (Table 4), and the calculated composition and measured properties were shown in Tables 2 and 3 as well.

Table 2. FFT characterization on composition, MBI, fines content, $\mathrm{pH}$, and EC.

\begin{tabular}{ccccccccc}
\hline Sample & $\begin{array}{c}\text { Solids } \\
\text { Content } \\
\text { (Weight \%) }\end{array}$ & $\begin{array}{c}\text { Bitumen } \\
\text { Content } \\
\text { (Weight \%) }\end{array}$ & $\begin{array}{c}\text { Water } \\
\text { Content } \\
\text { (Weight \%) }\end{array}$ & $\begin{array}{c}\text { MBI } \\
\text { (mEq100 g) }\end{array}$ & $\begin{array}{c}\text { Fines Content } \\
\text { Passing 325 Mesh } \\
\text { (Weight \%) }\end{array}$ & $\begin{array}{c}\text { pH } \\
\text { Conductivity } \\
\boldsymbol{\mu S S / c m )}\end{array}$ & $\begin{array}{c}\text { Sands to } \\
\text { Fines Ratio } \\
\text { (SFR) }\end{array}$ \\
\hline FFT-1 & 32.15 & 2.15 & 65.70 & 10.4 & 91.7 & 7.8 & 2216 & 0.09 \\
FFT-2 & 24.68 & 1.23 & 74.09 & 14.1 & 92.8 & 8.20 & 2900 & 0.08 \\
FFT-3 & 39.44 & 1.33 & 59.23 & 8.1 & 88.0 & 7.92 & 1320 & 0.14 \\
FFT-4 & 35.92 & 3.03 & 61.05 & 10.7 & 94.0 & 7.92 & 660 & 0.06 \\
$\begin{array}{c}\text { Diluted } \\
\text { FFT-3 }\end{array}$ & 23.25 & 0.78 & 75.97 & 8.1 & 88.0 & 7.86 & 1074 & 0.14 \\
$\begin{array}{c}\text { Diluted } \\
\text { FFT-4 }\end{array}$ & 23.10 & 1.95 & 74.95 & 10.7 & 94.0 & 7.80 & 947 & 0.06 \\
\hline
\end{tabular}

Table 3. Major cations and anions. Unit is $\mathrm{mg} / \mathrm{L}$.

\begin{tabular}{ccccccccc}
\hline Sample & $\mathbf{N a}^{+}$ & $\mathbf{K}^{+}$ & $\mathbf{C a}^{2+}$ & $\mathbf{M g}^{2+}$ & $\mathbf{C l}^{-}$ & $\mathbf{H C O}_{3}{ }^{-}$ & $\mathbf{S O}_{4}{ }^{2-}$ & $\mathbf{S A R}^{-}$ \\
\hline FFT-1 & 795.83 & 13.19 & 15.34 & 11.51 & 643.27 & - & 90.24 & 37.4 \\
FFT-2 & 305.90 & 23.01 & 12.80 & 3.65 & 137.90 & 392.94 & - & 9.3 \\
FFT-3 & 221 & 16.30 & 47.00 & 25.70 & 490 & 490 & 282.2 \\
FFT-4 & 96.60 & 11.60 & 20.70 & 10.50 & 150 & 150 & 174.2 & 4.3 \\
\hline
\end{tabular}

Table 4. The water analysis of OSPW: $\mathrm{pH}, \mathrm{EC}$, and major cations and anions (unit is $\mathrm{mg} / \mathrm{L}$ ).

\begin{tabular}{cccccccccccc}
\hline Sample & $\mathbf{p H}$ & $\mathbf{E C}(\mu \mathrm{S} / \mathrm{cm})$ & $\mathbf{N a}^{+}$ & $\mathbf{K}^{+}$ & $\mathbf{C a}^{2+}$ & $\mathbf{M g}^{2+}$ & $\mathbf{C l}^{-}$ & $\mathbf{F}^{-}$ & $\mathbf{H C O}_{3}{ }^{-}$ & $\mathbf{N O}_{3}{ }^{-}$ & $\mathbf{S O}_{4}{ }^{2-}$ \\
\hline OSPW & 8.29 & 949 & 162.16 & 9.57 & 37.70 & 12.70 & 32.44 & 3.72 & - & 17.05 & 241.60 \\
\hline
\end{tabular}

Two anionic polyacrylamide flocculants, polymer NRG1000 and A3338, produced by SNF Canada, were used in this study. The characterization of the two polymers is shown 
in Table 5. All polymer solutions were prepared at a concentration of $0.45 \mathrm{wt} \%$ in OSPW and allowed to hydrate for at least $1 \mathrm{~h}$ before use.

Table 5. Characterization of polymers A3338 and NRG1000.

\begin{tabular}{|c|c|c|c|c|c|c|c|}
\hline \multirow{2}{*}{ Sample } & \multirow{2}{*}{$\begin{array}{l}\text { Charge } \\
\text { Density }\end{array}$} & \multirow{2}{*}{$\begin{array}{c}\text { Molecular } \\
\text { Weight }\end{array}$} & \multirow{2}{*}{$\begin{array}{l}\text { Bulk Density } \\
\left(\mathrm{kg} / \mathrm{m}^{3}\right)\end{array}$} & \multicolumn{3}{|c|}{ Brookfield Viscosity (cP) } & \multirow{2}{*}{$\begin{array}{l}\text { Particle Size } \\
(\mathrm{mm})\end{array}$} \\
\hline & & & & at $5.0 \mathrm{~g} / \mathrm{L}$ & at $2.5 \mathrm{~g} / \mathrm{L}$ & At $1.0 \mathrm{~g} / \mathrm{L}$ & \\
\hline A3338 & High & High & $0.6-0.9$ & 1520 & 570 & 250 & $0.15-2$ \\
\hline NRG1000 & Medium & Low & 0.80 & 1250 & 450 & 150 & $0.15-2$ \\
\hline
\end{tabular}

\subsection{Equipment}

The setup for flocculation consists of a vessel with a baffle, an impeller, a peristaltic pump (coleparmer Drive/DISP MFLX BENCH 115/230) for polymer injection, and an overhead mixer (Heidolph Hei-Torque 100 Precision Base) capable of monitoring the torque exerted on the impeller shaft during the mixing (Figure 1). Three types of vessels were used in this study: 4" metal cup with a built-in baffle [13], 6" metal cup with an inserted baffle, and a glass beaker with an inserted baffle (Figure $2 a-c$ ).

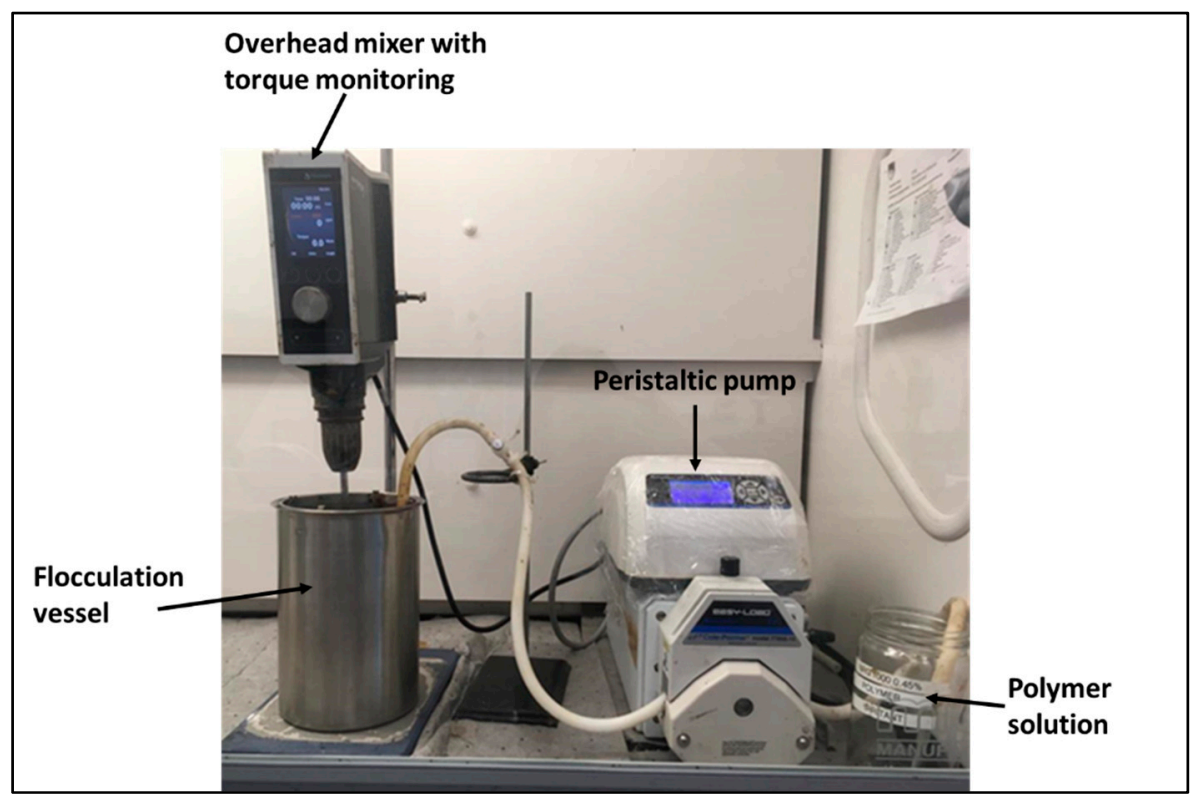

Figure 1. Flocculation setup.

\subsection{Homogenization of FFT}

During storage, larger particles tended to settle out of the FFT over time. The following procedure was used to homogenize and subsample the desired volume of FFT from a $20 \mathrm{~L}$ bucket for each flocculation vessel. (1) Homogenize FFT for 10 min using a drill mixer with a paint-mixing attachment (Figure $2 \mathrm{~d}$ ). When homogenizing the drill mixer was kept below the sample surface to minimize entrainment of air which could also influence flocculation performance. (2) Measure solids content to confirm the FFT was homogenized. (3) Measure density and calculate the mass of FFT required for $300 \mathrm{~mL}$ of FFT for 4 " cup testing, $1000 \mathrm{~mL}$ of FFT for 6" cup testing, or 230-270 mL of FFT for $1000 \mathrm{~mL}$ glass beaker testing. (4) Re-homogenize FFT for $10 \mathrm{~s}$ with the drill mixer before each subsampling on the same day testing. (5) Subsample the calculated mass of FFT into the flocculation vessel. 

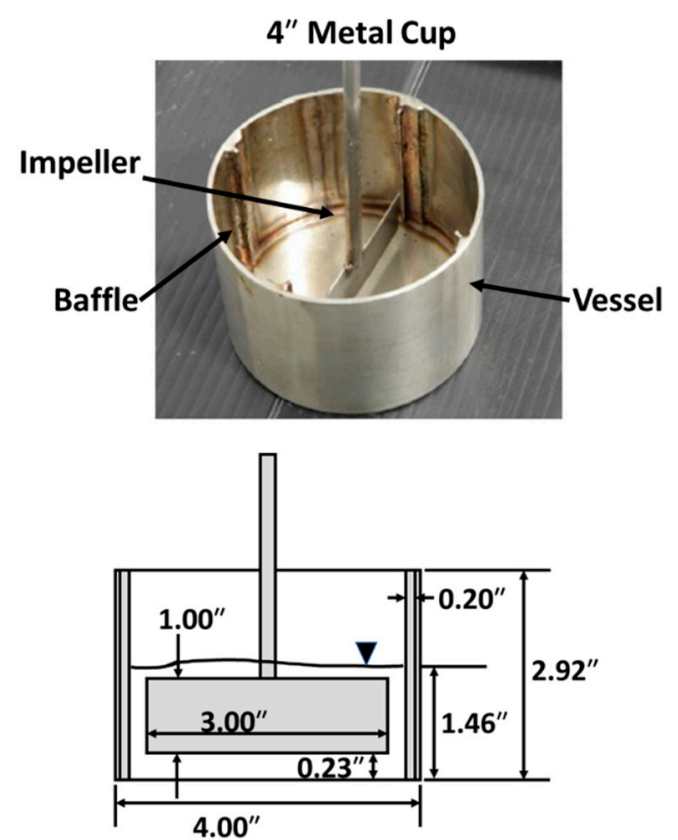

(a)

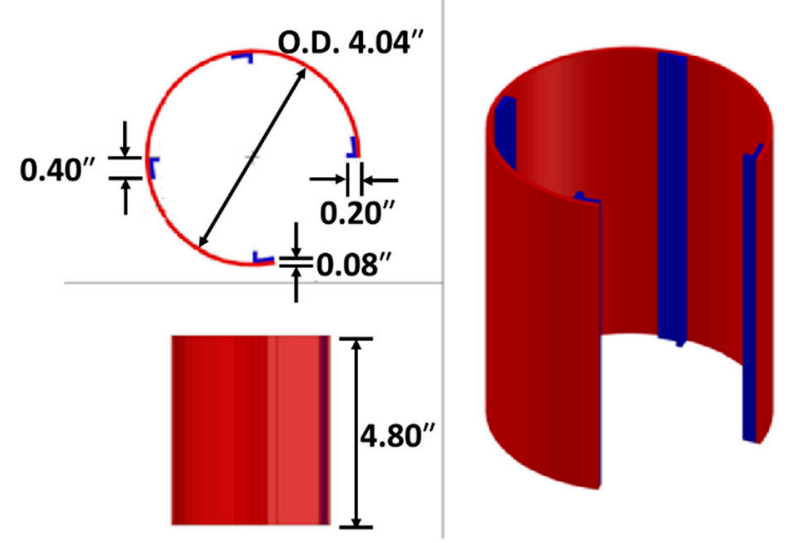

(c)

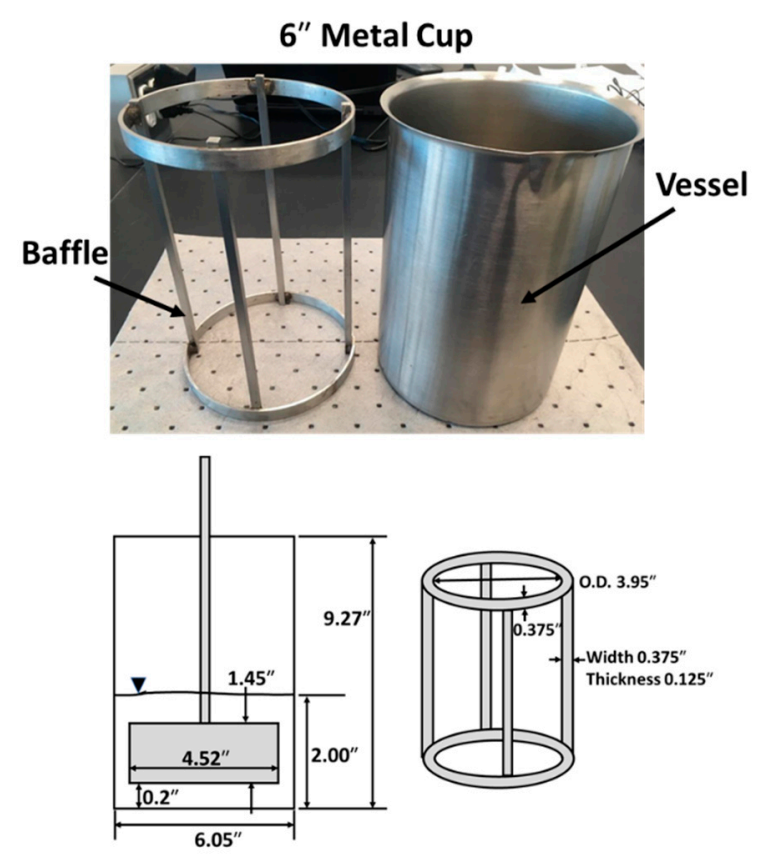

(b)

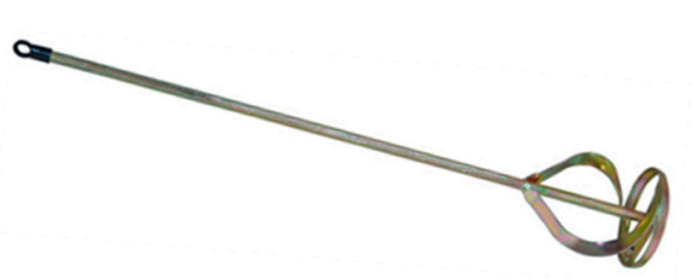

(d)

Figure 2. Schematic dimensions of flocculation vessels, baffles, and impellers: (a) 4" metal cup setup for flocculation; (b) 6" metal cup setup for flocculation; (c) dimension of the baffle for a $1000 \mathrm{~mL}$ of glass beaker as the flocculation vessel; (d) paint-mixing impeller for the FFT homogenization.

\subsection{Flocculation of FFT}

The desired mass of FFT was subsampled into the flocculation vessel. The volume of FFT required was determined based on the ability to place the mixing impeller in a central position in the flocculation vessel. The mass of FFT was then calculated based on the average FFT density. Mass was used for each subsample rather than volume to ensure a consistent sample and that air entrainment did not alter the amount of sample substantially. The baffled vessel with the sample was assembled onto the overhead mixer with the impeller. The FFT was pre-sheared until a stable torque was observed in order to remove thixotropic effects that may be present due to the handling of the FFT prior to testing [13]. For consistency, pre-shearing for $1 \mathrm{~min}$ at $300 \mathrm{rpm}$ was conducted for all the flocculations in this study. Once the minute of pre-shearing was completed, the polymer solution was injected into the vessel at a pre-determined rate $(20 \mathrm{~mL} / \mathrm{s}$ in this study). The injection position was $0.5 \mathrm{~cm}-1 \mathrm{~cm}$ below the surface of the FFT slurry. The torque reading on the overhead mixer was monitored during the mixing process. Once the peak or max 
torque was reached, the mixing speed was reduced immediately to $50 \mathrm{rpm}$ and the mixing was continued at $50 \mathrm{rpm}$ for $15 \mathrm{~s}$.

The measurement method of the dewatering performance was conducted using immediate drainage of a flocculation slurry for $24 \mathrm{~h}$ using \#18 mesh sieves or kitchen sieves with the same opening (1 mm) (Figure 3) [13]. After $24 \mathrm{~h}$ drainage, the solids content of the flocs was measured by subsampling flocs into a small aluminum pan placed in an oven at $100{ }^{\circ} \mathrm{C}$ for overnight drying. The release water was collected and measured to determine mass, clarity, and color.

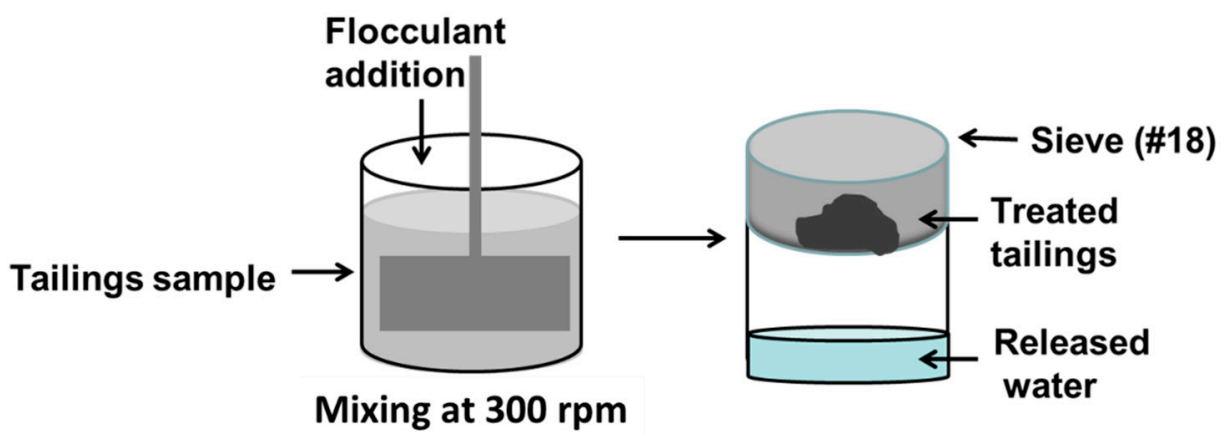

Figure 3. The process of $24 \mathrm{~h}$ drainage test on dewatering performance.

\subsection{Color and Clarity of Release Water}

The color of the release water from the treated FFT was measured according to a self-made 5-scale category (Figure 4a): 0—clear and colorless; 1 -pale yellow; 2-yellow or light brown; 3-brown; and 4-black. The clarity of the release water was measured by a clarity wedge with 0-46 scales donated by SNF Canada (Figure 4b).

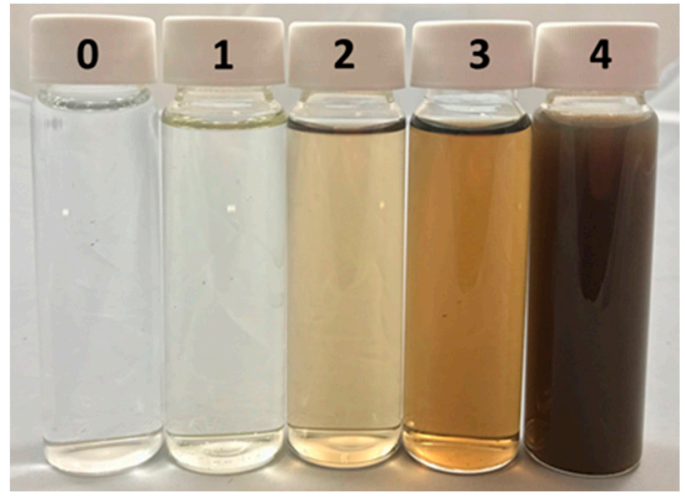

(a)

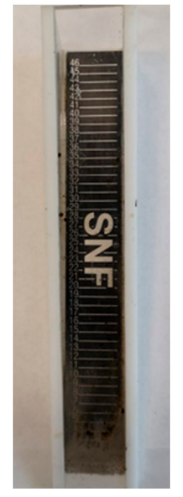

(b)

Figure 4. (a) Torque profiles of the flocculation on A3338-treated FFT-4 with different dosages; (b) The net water release (NWR) results corresponding to the torque profiles of the flocculation.

\section{Results}

\subsection{Effect of Polymer Dosage}

In general, the flocculation performance of the polymer increases with the dosage up to a certain optimum point and then decreases with further addition of the polymer due to the repulsion between the polymer-covered particles [14]. A full dosage response curve is recommended to determine the dewatering performance of polymer treated FFT. For a full dosage curve, a single shot injection of polymer solution is performed from under-dosed conditions (low dewatering performance) to an optimal dosed condition (highest dewatering performance), and then to an over-dosed condition (low dewatering performance) [13]. In the optimal dosage range as shown in Figure 5, large flocs were 
observed and separated from the slurry resulting in visible release water; meanwhile, in the underdose and overdose ranges, small or no flocs were formed and no release water could be observed in the slurry. Single or fixed dosage comparisons may lead to false results and decisions as different high-density slurries have different compositions and water chemistries, resulting in different dosage responses to the same flocculant, which impacts the flocculation performance [9]. Different flocculants have different molecular weights, charges, structures, chemical composition, viscosities, and hence impact on flocculation performance as well. Testing over the range of conditions that could be seen rather than attempting to achieve a "representative" sample is important in order to properly evaluate technology for use.

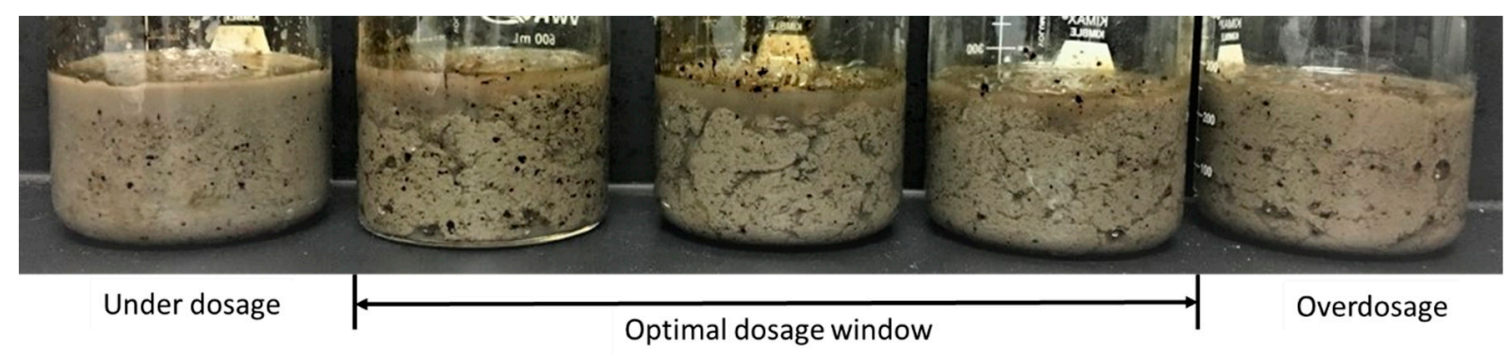

Figure 5. Photos of polymer A3338-treated FFT-1 at under dosage, optimal dosages, and over dosage.

Figure 6 shows dosage response curves of different FFT treated with polymer A3338, with dosage curves based on g/ton solids (Equation (1)) corresponding to the net water release (NWR) (Equation (2)) after $24 \mathrm{~h}$ drainage. The higher the NWR, the better the dewatering performance for the target application. Each flocculated FFT in Figure 6 shows the highest dewatering performance at optimal polymer dosage. At optimal dosages, the A3338-treated FFT-2 and A3338-treated FFT-3 had comparable dewatering performance according to the NWR ( 18\%). The A3338-treated FFT-2 (12\% NWR), however, had much higher dewatering performance than A3338-treated FFT-3 (6.5\% NWR) at the fixed dosage of $1800 \mathrm{~g} /$ ton solids. Therefore, acquiring full dosage response curves is highly recommended to evaluate high-density slurry dewatering performance.

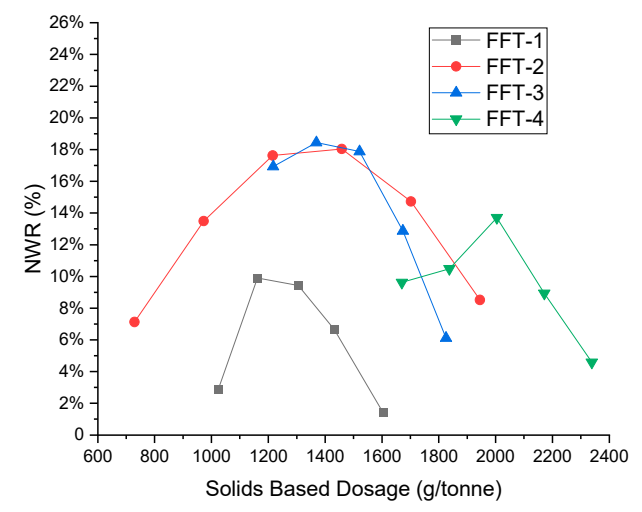

Figure 6. Dosage curves of 4 different FFT treated with polymer A3338: dosage curves are plotted by NWR versus solids based dosage. Each dot is the average value of duplicate or more testing results.

Solids based polymer dosage $(\mathrm{g} / \mathrm{ton})=$

Volume of polymer solution $(\mathrm{mL}) \times$ density of polymer solution $(\mathrm{g} / \mathrm{mL}) \times$ concentration of polymer solution $(\mathrm{wt} \%)$ Weight of FFT $(\mathrm{g}) \times$ solids content $(\mathrm{wt} \%)$

$$
\text { NWR }=\frac{\text { Water release from initial FFT }}{\text { Water in initial FFT }}=\frac{\text { Water release after } 24-\text { hour draining }- \text { Added polymer solution }}{\left.\frac{\text { Water in initial FFT }}{\text { Water weight } \% \text { in FFT }}\right)}=1-
$$




\subsection{Effect of Mixing}

The efficacy of mixing relies on a combination of factors, including mixing energy (speed and time), geometry of vessel (with or without baffles), geometry of impeller, solids content of slurry, etc. Baffles are highly recommended for effective mixing of high-density slurries, but no limitations are placed on the type of impeller, energy, or solid concentration as long as basic minimum flocculation requirements are met [15]. Flocculation in a small-scale jar is often done poorly, with inconsistent mixing, and lack of repeatability and reproducibility because the mixing process used to rely on operators visual observations. The determination of flocculation via the operators' observation heavily relies on the operators' experience, which required a large amount of training and practicing on flocculations. The 6 " metal beakers used in this study made the visual observation impossible due to the height of the vessel and safety concerns. Inappropriate mixing can lead to wrongly interpreted results, and time and cost wasted. This study used a torque-oriented mixing technique that allowed the operators to determine the flocculation stages in real-time by monitoring the torque progress and stopping the mixing process at well-defined cues to obtain good flocculation results. This mixing technique was based on the principles described in the Floccky Tester, manufactured by Koei Industry Co., Ltd. (Kakogawa, Hyogo, Japan) and adapted for oil sands in Suncor's patent [16].

The development of torque-oriented mixing procedures was based on the rheological changes that occurred during the flocculation process: premixing, polymer injection, polymer dispersion, under mixed, water release, and over sheared [13]. A visual representation of different flocculating stages corresponding to torque progress is presented in Figure 7. During the pre-mixing, the FFT was observed to be well homogenized, exhibiting streaming birefringence (white swirls). Thixotropic effects of the FFT samples were expected to be removed after pre-mixing [13]. As soon as the polymer was injected, the white swirls disappeared, and the small bitumen droplets were observed. As mixing continued, the polymer was dispersed in the FFT and flocs began to form, as evidenced by the appearance of structure within the image. The viscosity of the slurry increased, resulting in the increased force on the impeller. After flocs of maximum size were formed, water channels and air pocket formation became more apparent. When mixing was continued into the "over-sheared stage", the flocs structure began to grow smaller, and the separated water became re-incorporated into the flocs.

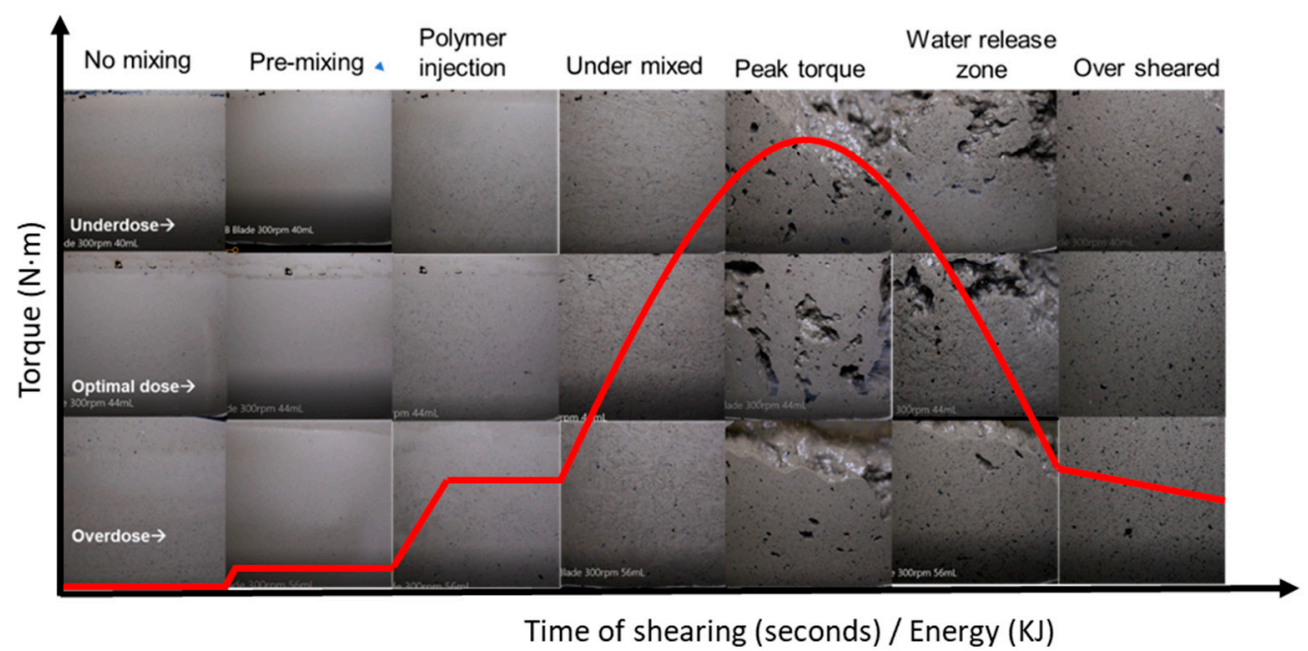

Figure 7. Visual distinction corresponding to the stages of flocculation and torque progress. The red line represents the torque progress during the flocculation.

By monitoring the impeller shaft torque over time, the various stages of the flocculation process can be precisely monitored and identified in real-time. The observations on the flocculation stages were well aligned with the features in the torque profile. The shapes 
of the torque profile were observed to be an indicator of polymer dosage (Figure 8a). Increasing polymer dosage tended to delay the appearance of the torque peak and broadened the overall shape of the curve. This was most likely because a large amount of polymer required more time to be fully dispersed within the high density slurry, and more time to become fully flocculated with clay particles. Oversaturation of clay surfaces and steric repulsion could explain why the torque peak values began to decrease after a critical polymer dosage.

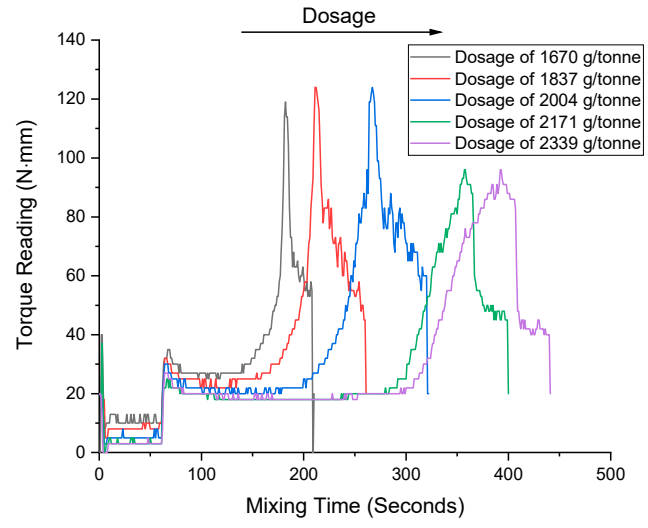

(a)

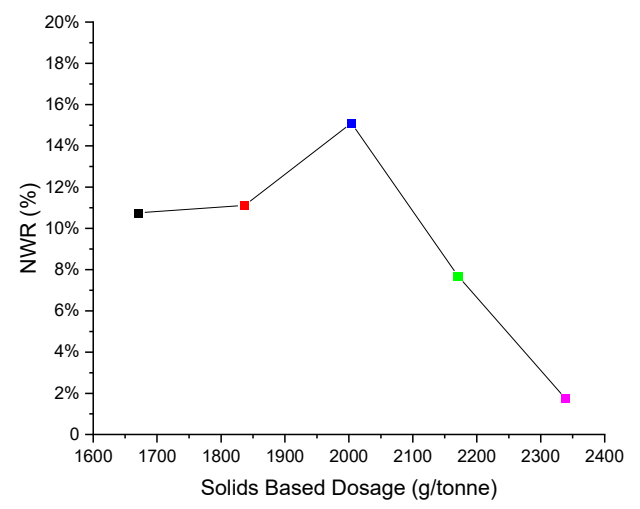

(b)

Figure 8. (a) Torque profiles of the flocculation on A3338-treated FFT-4 with different dosages; (b) the NWR results corresponding to the torque profiles of the flocculation.

Besides the mixing energy (speed and time), the geometry of impeller used for mixing is also a key factor affecting the flocculation efficacy. Two types of impeller, flat mixer and auger mixer (Figure 9), were studied on the flocculation of three FFT samples using a $1 \mathrm{~L}$ glass beaker with a baffle. The auger mixer tended to provide gentler mixing and required a longer time to form dense flocs than the flat mixer (Figure 10a). The flocs tended to form abruptly by auger mixer and were more easily over-sheared than using the flat mixer. The geometry of impeller has different influences on different FFT samples. FFT-3, which has higher sand content and low clay content, was more influenced by the geometry of mixers during the flocculation (Figure 10b), probably because the auger mixer could pick up the sand from the bottom of the slurry and mix them in.

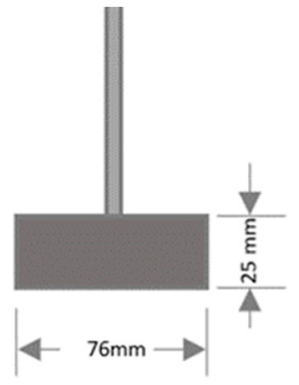

(a)

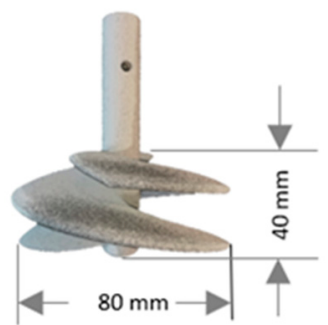

(b)

Figure 9. Geometries of mixing impellers: (a) flat mixer; (b) auger mixer. 


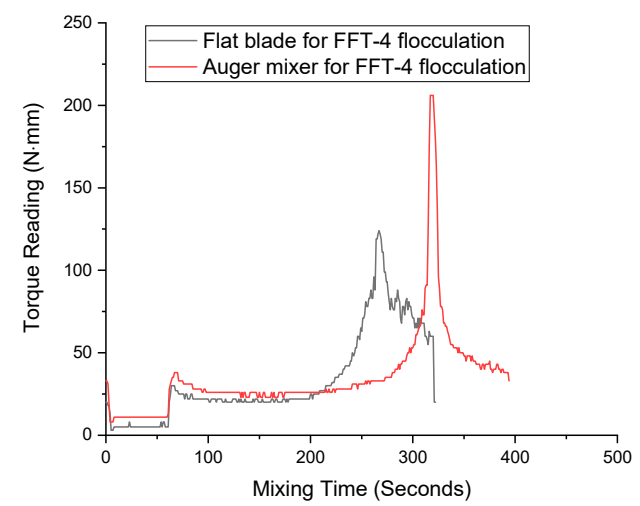

(a)

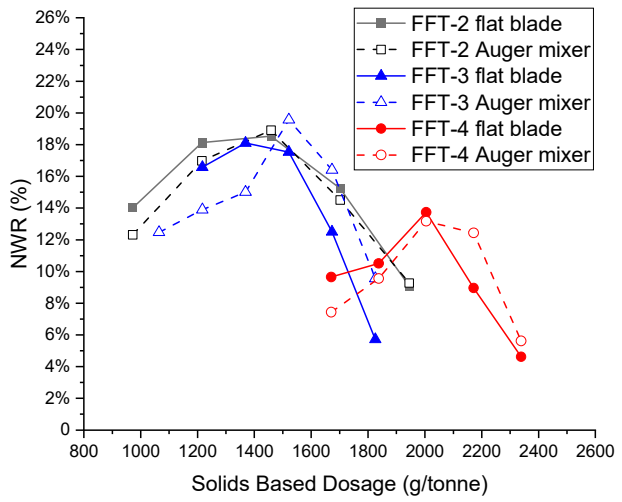

(b)

Figure 10. The influence of geometry of mixers on flocculation: (a) torque readings by flat mixer and auger mixer during the flocculation of FFT-4 with polymer A3338; (b) dosage curves of three FFT samples flocculated by A3338 using flat mixer and auger mixer, respectively. Each dot is the average value of duplicate or more testing results in (b).

\subsection{Effect of Dilution}

Dewatering performance of high density slurry is usually sensitive to solids concentration. As shown in Figure 11a, the diluted FFT samples had much lower NWR than the undiluted samples when the water added to dilute the FFT was considered for the calculation of NWR (Equation (3)). As a result, the dewatering products of diluted FFT samples had lower solids contents in flocs (Figure 11b). Therefore, FFT dilution might not be a good practice for tailings treatment, assuming the degree of dewatering is the main performance indicator of interest. NWR for diluted FFT $=\frac{\text { Water release from initial FFT }}{\text { Water in initial FFT }}=1-$
\[ (1-\text { solids weight } \% \text { in flocs }) \]

Water weight $\%$ in diluted FFT - added water weight $\%$ for dilution

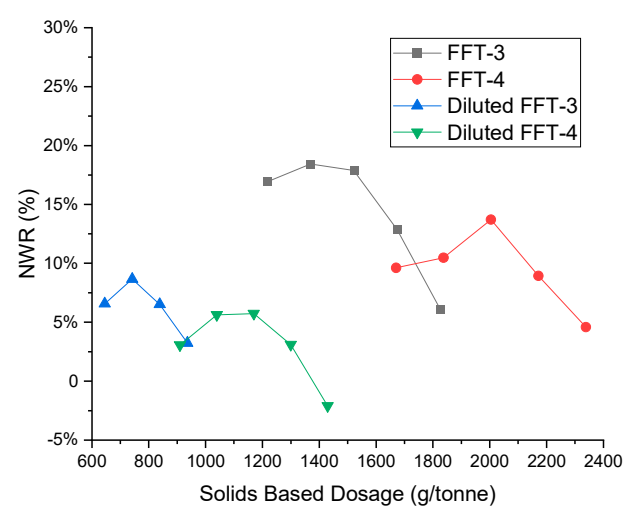

(a)

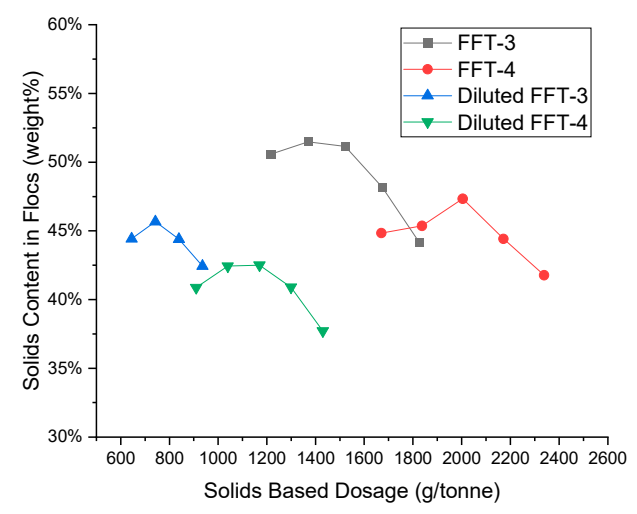

(b)

Figure 11. Dosage curves of 2 FFT and diluted FFT samples treated with polymer A3338: (a) NWR results corresponding to the polymer dosage; $(\mathbf{b})$ the solids content in flocs corresponding to the polymer dosage. Each dot is the average value of duplicate or triplicate testing results.

\subsection{Effect of Clays}

FFT-2, diluted FFT-3, and diluted FFT-4 had comparable solids content in the untreated FFT samples. However, they have different dewatering performances according to NWR when treated with polymer A3338 (Figure 12a). This is because the three FFT samples 
had very different clay activities. Clays are a common component in most tailings slurries, especially in FFT. The water-holding capacity of clays dominates the behavior of FFT and hinders the dewatering performance due to the large surface area and reactivity of clay particles, even when they are present in small proportions $[17,18]$. The MBI is a simple index test that provides an indication of clay activity [11]. The dry clay content of FFT is determined by an empirically derived conversion between MBI and the $\%$ clay mineral as measured by X-ray diffraction (XRD) and particle size distribution (PSD), published by Amar Sethi on 70 Suncor tailings samples (Equation (4)) $[19,20]$. As shown in Table 6, FFT-2 has the highest MBI and \% clay and hence the lowest dewatering performance of NWR (Figure 12a), while diluted FFT-3 with the lowest MBI and \% clay provided the highest dewatering performance by presenting the highest NWR.

$$
\% \text { Clay }=(\mathrm{MBI}(\mathrm{mEq} / 100 \mathrm{~g})+0.04) / 0.14
$$

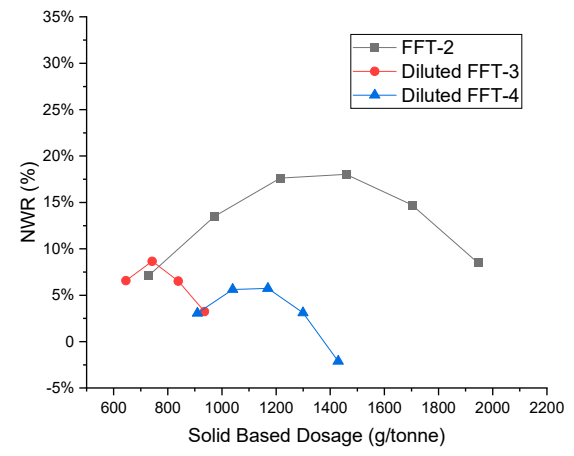

(a)

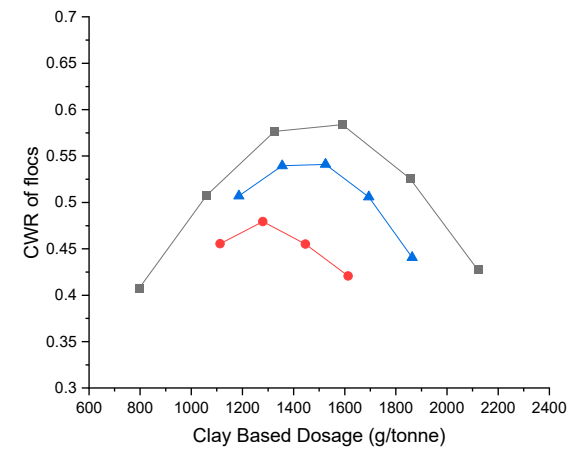

(b)

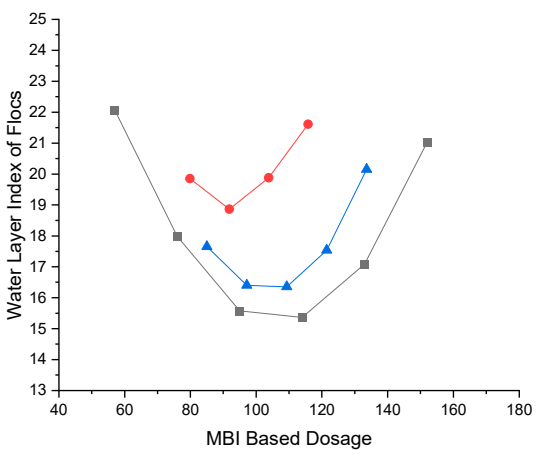

(c)

Figure 12. Dosage curves of FFT-2, diluted FFT-3, and diluted FFT-4 treated with polymer A3338: (a) NWR results corresponding to solid based polymer dosage; (b) CWR of flocs corresponding to clay based dosage; (c) water layer index of flocs corresponding to MBI based dosage. Each dot is the average value of duplicate or more testing results.

Table 6. The measured MBI value, calculated \% clay and CWR results of FFT-2, diluted FFT-3, and diluted FFT-4.

\begin{tabular}{cccc}
\hline FFT & Solids Content (Weight\%) & $\begin{array}{c}\text { MBI } \\
(\mathbf{m E q} / \mathbf{1 0 0} \mathbf{~ g})\end{array}$ & \% Clay \\
\hline FFT-2 & 24.68 & 14.1 & 101.0 \\
Diluted FFT-3 & 23.25 & 8.1 & 58.1 \\
Diluted FFT-4 & 23.10 & 10.7 & 76.7 \\
\hline
\end{tabular}

The relationship between clays and water associated with clays in the treated tailings or the tailings deposit is a critical parameter in defining tailings management performance. 
Clay-to-water ratio (CWR), which is calculated from dry clay content (Equation (5)), has been used by oil sands industries and tailings researchers to compare the properties of treated tailings, despite the variations in solids between different tailings samples [18]. Higher CWR in the treated FFT presents that the higher clays are flocculated to the final product and less water content is associated with the clays. It was also found that polymer dosing on a dry solid basis often resulted in under dosage or overdosage, but it was found to be consistent in terms of dry clay content (Equation (6)) [21]. Corresponding to the polymer A3338 treatment, FFT-2 produced the most dewatered material (highest CWR of flocs) compared to diluted FFT-3 and diluted FFT-4 with a slightly higher required optimal dosage (Figure 11b).

$$
\begin{aligned}
\text { CWR }= & (\text { Solids content weight } \% * \text { Clay } \%) /(\text { Water content weight } \%) \\
& \text { Dry clay based dosage }=\text { Solids based dosage } / \% \text { Clay }
\end{aligned}
$$

Since the clay\% is determined by an empirically derived conversion and is specific to a single set of samples taken from a single Suncor tailings pond in the 1970s, it tends to lead to confusion as the "\%" clay calculated can be over $100 \%$ if more smectite is present than was in the original sample set [22]. For this reason, the CWR derived from the empirical value \%clay is a confusing metric. The thickness of the adsorbed water layer on the surfaces of clay minerals depends on the total amount of water and the active surface area of clays in a sample [23]. The thickness of the adsorbed water layer, named water layer index in this study, can be calculated using Equation (7), whereas the total surface area of clays is determined by MBI (Equation (8)) [22]. This is a conversion based on the assumption of a monolayer of methylene blue adsorbed on all available clay surfaces [11,24]. This water layer index is closer to the direct measurement value and allows for an easier translation of Derjaguin-Verwey-Landau-Overbeek's (DLVO) theory into the performance of the system. Therefore, the water layer index is preferred for future academic publications, and should be used to report the tailings management performance for a given technique. The higher the water layer index, the lower the CWR in a sample and the lower the tailings management performance, as shown in Figure 12c. For the same reason, the MBI based dosage (Equation (9)) is useful when comparing between feeds in controlled settings, even though a solid based dose is more relevant in the field.

Thickness of water layer $(\mathrm{nm})=\left(\right.$ Water content $\left.(\mathrm{g} / \mathrm{g}) \times 10^{9}\right) /\left(\right.$ Total surface area $\left(\mathrm{m}^{2} / \mathrm{g}\right) \times$ Density of water $\left.\left(10^{6} \mathrm{~g} / \mathrm{m}^{3}\right)\right)$

$$
\text { Total surface area }\left(\mathrm{m}^{2} / \mathrm{g}\right)=\mathrm{MBI} \times \mathrm{SA}_{\mathrm{mb}} \times 0.06022 \mathrm{~m}^{2} / \mathrm{g}
$$

where $\mathrm{SA}_{\mathrm{mb}}$ is the surface area of a methylene blue molecule $\left(1.3 \mathrm{~nm}^{2} /\right.$ molecule $)$, and $0.06022 \mathrm{~m}^{2} / \mathrm{g}$ is Avogadro's constant.

$$
\text { MBI based dosage }(\mathrm{g} / 10 \text { equivalent })=\text { Solids based dosage } / \mathrm{MBI}
$$

\subsection{Effect of Water Chemistry}

Water chemistry of high density slurry is an often underestimated factor affecting the dewatering performance. The oil sands tailings usually have a $\mathrm{pH} 7.5-9$ due to bitumen extraction process requirements. Alkaline conditions cause the ionization of ionic polyacrylamide flocculants and increase the mutual repulsion between negatively charged groups, resulting in extended polymer chains. The conformation of extended chains favors bridging flocculation. On the other hand, the $\mathrm{pH}$ around 7.5-9 also allows the SAR to affect the clays behavior [25]. The SAR value was used to determine whether the water chemistry is prone to generating dispersive slurries. Slurries with high SAR values tend to be alkali and undergo colloidally dispersive inhibiting flocculation, while slurries exhibiting low SAR values tend to be naturally coagulated and settling [25]. In this study, the FFT-1, which has a higher SAR, resulted in a lower dewatering performance than FFT-4 with the comparable MBI and $\mathrm{pH}$ in water chemistry (Table 7). 
Table 7. The comparison of SAR, MBI, pH, and NWR between FFT-1 and FFT-4.

\begin{tabular}{ccccc}
\hline FFT & SAR & $\begin{array}{c}\text { MBI } \\
(\mathbf{m E q} / \mathbf{1 0 0} \mathbf{g})\end{array}$ & $\mathbf{p H}$ & $\begin{array}{c}\text { NWR } \\
\mathbf{( \% )}\end{array}$ \\
\hline FFT-1 & 37.4 & 10.4 & 7.80 & 9.9 \\
FFT-4 & 4.3 & 10.7 & 7.92 & 13.7 \\
\hline
\end{tabular}

\subsection{Other Effects}

Many other factors could influence the flocculation efficiency and repeatability, such as polymer injection location and injection rate, concentration of polymer solution, the location and height of mixer, the geometry of baffle, etc. For example, choosing the optimal polymer injection rate is critical for a polymer solution with a certain viscosity and concentration. A high polymer injection rate could lead to local overdosing, reducing flocculant efficiency. In Figure 13, FFT-1 was flocculated by the polymer NRG1000 at two different solution injection rates- $84 \mathrm{~mL} / \mathrm{s}$ and $33 \mathrm{~mL} / \mathrm{s}$. The flocs obtained from the higher injection rate appeared visibly muddier, indicating worse flocculation performance than the lower injection rate (Figure 13). One the other hand, a low polymer injection rate would result in local over-shearing, reducing flocculation efficiency as well. According to Bourne's summation, flocculation is a process dominated by mesomixing [8]. The condition that provides high dewatering performance for one polymer and high density slurry might not work for another polymer and high density slurry. It is highly recommended to choose the most suitable and repeatable flocculation parameters according to the expectation of the experiment.

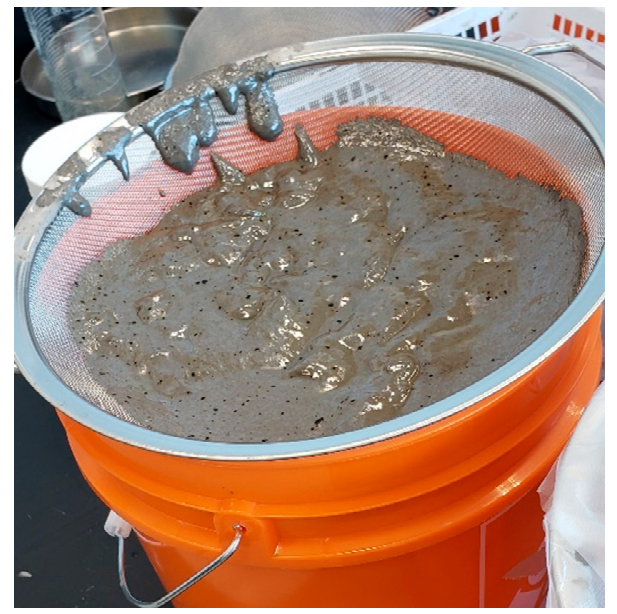

(a)

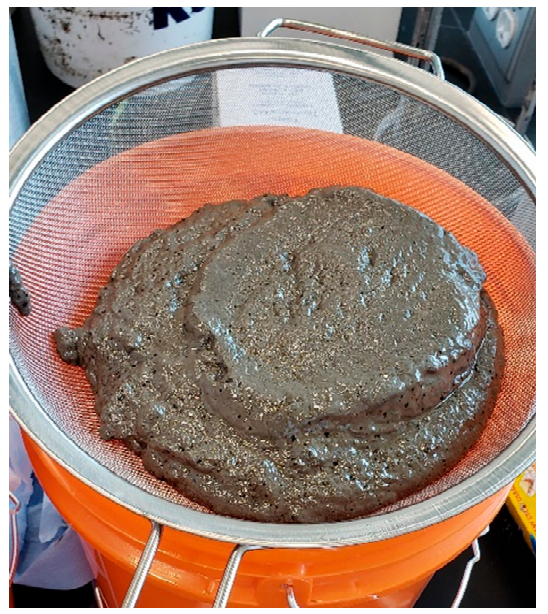

(b)

Figure 13. Flocculated FFT-1 by polymer NRG1000 at the same polymer dosage: (a) polymer solution injection rate at $84 \mathrm{~mL} / \mathrm{s}$; (b) polymer solution injection rate at $33 \mathrm{~mL} / \mathrm{s}$.

\subsection{Example of Polymer Evaluation on FFT Treatment}

A robust flocculation method is the key to evaluate various flocculants for tailings treatment. The improved testing repeatability and reproducibility by the torque-oriented mixing allows the polymer evaluation and screening to be more credible, and improves the ability to confidently discern performance differences between different polymers. Figure 14 shows the comparison of dewatering performance of polymer A3338 and polymer NRG1000 on the FFT-1. Repeating the tests, choosing the average values and using the statistical analysis to determine the optimal dosage or optimal dosage window were critical to determine dewatering performance, because a single testing result would lead to wrong decisions on the polymer evaluation. If the best flocculation results of the repeated tests were chosen for evaluation as shown in Figure 14b, the optimal dosage of polymer A3338 was $123 \mathrm{~g}$ of MBI based dosage, and dewatering performance on FFT-1 was worse than 
polymer NRG1000. The average values with statistical analysis in Figure 14a, however, shows that both polymers had a broad optimal dosage window and the dewatering performances had no significantly statistical difference. It is recommended to use multiple KPIs including NWR or water layer index of flocs, release water quality (clarity and color), dosage, water chemistry of release water, etc. to build technical and economic analysis criteria which meet the researchers' needs for polymer evaluation. If the water quality of the release water from the treated FFT is a critical factor to the researcher, polymer A3338 has better dewatering performance than polymer NRG1000 due to the higher clarity and lower color scales of the release water (Figure 14c,d).

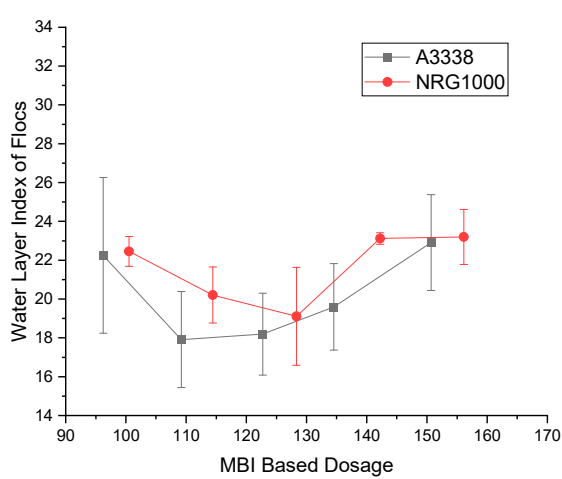

(a)

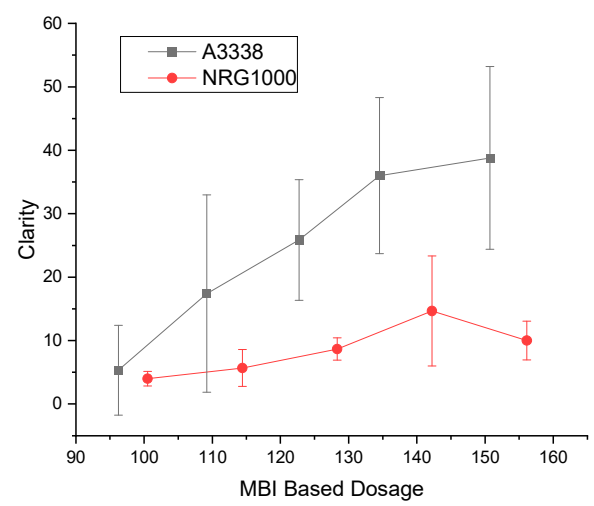

(c)

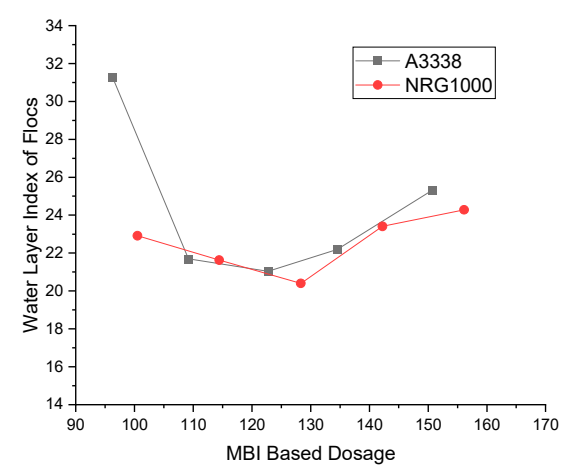

(b)

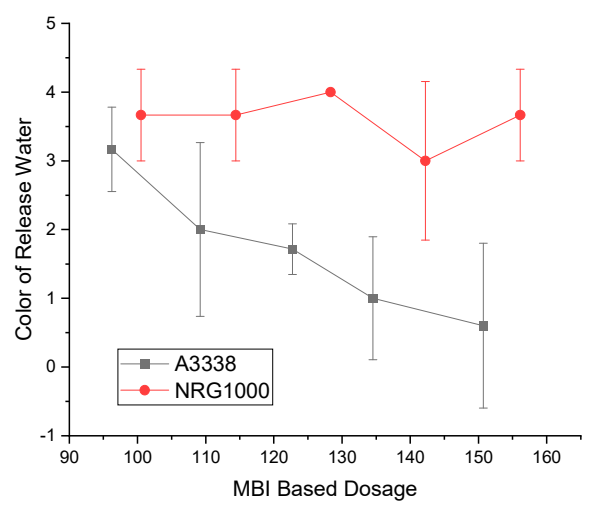

(d)

Figure 14. The comparison of two polymers A3338 and NRG1000 in case of FFT-1 dewatering: (a) the average dewatering results with 95\% confident index error bars; (b) the best dewatering results; (c) the average clarity numbers of the release water with 95\% confident index error bars; (d) the average color scales of the release water with $95 \%$ confident index error bars.

\section{Conclusions}

Flocculation of high density slurry is not a simple process, and the dewatering performance is affected by many critical factors including mixing conditions, feed characteristics, polymer types, and dosages. When evaluating new polymers or determining if an old one is appropriate for a new application, it is therefore important to consider all of the factors in testing.

The dewatering performance of the polymer A3338 treated FFT shows that the NWR results can be reduced from $18 \%$ at the optimal dosage to $7 \%$ at the underdosage and overdosage. Single or fixed dosage comparison may lead to false results and decisions, because different types of FFT have different dosage responses to the same flocculant. 
Acquiring full dosage response curves are necessary to screen flocculants and evaluate the dewatering performance of high density slurries.

Mixing conditions are application specific, and hence understanding the degree of shear expected at different parts of the process can be very helpful to develop a bench scale test plan. If the specific mixing conditions are not well understood, it is important to select several different mixing conditions and control them well when testing new polymers. This includes controlling polymer injection position, polymer injection rate, vessel geometry, and mixing speed. Results reveal that the dewatering performance of flocculated FFT can be improved from no release water to $10 \%$ NWR when the polymer injection rate decreases from $84 \mathrm{~mL} / \mathrm{s}$ to $33 \mathrm{~mL} / \mathrm{s}$. Using a device that measures torque during flocculation is highly recommended to achieve repeatable and reproducible dewatering performance. Reducing the mixing speed at the peak torque and avoiding over-shearing are critical to obtaining the optimal dewatering performance of high density slurry.

Even more important to consider in testing is the feed characteristics for the comparison of the dewatering performance. Achieving a high dewatering performance is easier in a low clay slurry and low SAR slurry. For similar types of FFT treated by the same flocculant, decreasing the SAR value of the slurry can improve the dewatering performance.

For better evaluation of different polymers' dewatering performance, polymers should be compared across multiple feeds, and across multiple dosages in replicate in order to choose optimal performance. If multiple feeds cannot be obtained from a site, ensure complete characterization of the feed received and, if possible, adjust the feed via dilution or other reasonable perturbations to see the effect.

Finally, it is important that a range of dosages be tested with sufficient replication. While time consuming, this level of testing provides important insight which can be used to achieve better field performance at a fraction of the cost of extensive field testing.

Author Contributions: Conceptualization, H.K. and Y.L.; methodology, H.K. and Y.L.; validation, X.Y.G., Y.S.S., M.G. and A.S.; formal analysis, Y.L.; investigation, H.K. and Y.L.; data curation, Y.L.; writing-original draft preparation, Y.L.; writing-review and editing, H.K.; supervision, H.K.; project administration, Y.L. and H.K.; funding acquisition, H.K. and A.S. All authors have read and agreed to the published version of the manuscript.

Funding: The research was funded by the Natural Science and Engineering Research Council of Canada (NSERC), Institute for Oil Sands Innovation (IOSI) at the University of Alberta, and Suncor Energy Inc.

Institutional Review Board Statement: Not applicable.

Informed Consent Statement: Not applicable.

Data Availability Statement: Data is contained within the article.

Acknowledgments: The authors acknowledge the staff from Alberta Innovates Ted Garver and Wei Li for the camera and light setup for taking photos.

Conflicts of Interest: The funders had no role in the design of the study, in the collection, analyses, or interpretation of data; in the writing of the manuscript; but have reviewed the results and approved publication.

\section{References}

1. Cooke, R.; Paterson, A.J.C. The Design of Slurry Pipeline Systems: 16-19 March 2004; Paterson \& Cooke Consulting Engineers (Pty) Ltd.: Cape Town, South Africa, 2004.

2. Paterson, A.J.C. High density slurry and paste tailings, transport systems. In Platinum Adding Value; South Africa Institute of Mining and Metallurgy: Johannesburg, South Africa, 2004; pp. 159-166.

3. Technical Guide for Fluid Fine Tailings Management. Oil Sands Tailings Consortium and COSIA. Available online: https: / / www.cosia.ca/uploads/documents/id7/TechGuideFluidTailingsMgmt_Aug2012.pdf (accessed on 3 February 2021).

4. Schoenbrunn, F. Dewatering to higher densities-An industry review. In Proceedings of the 14th International Seminar on Paste and Thickened Tailings, Perth, Australia, 5-7 April 2011; Jewell, R., Fourie, A.B., Eds.; Australian Centre for Geomechanics: Crawley, WA, Australia, 2011; pp. 19-23. 
5. Sobkowicz, J. Oil Sands Tailings Technology Deployment Roadmap. Available online: https://cosia.ca/sites/default/files/ attachments/Tailings\%20Roadmap\%20Volume\%202\%20June\%202012.pdf (accessed on 3 February 2021).

6. $\quad$ Revington, A.P.; Omotoso, O.; Wells, P.S.; Hann, T.C.; Weiss, M.H.; Bugg, T.; Eastwood, J.; Young, S.J.; O’Neill, H.R.; Sanchez, A.C. Process for Flocculating and Dewatering Oil Sand Mature Fine Tailings. U.S. Patent 10590347B2, 6 March 2018.

7. Hogg, R. Flocculation and dewatering. Int. J. Miner. Process 2000, 58, 223-236. [CrossRef]

8. Bourne, J.R. Mixing and the selectivity of chemical reactions. Org. Process Res. Dev. 2003, 7, 471-508. [CrossRef]

9. Fawell, P.D.; Costine, A.D.; Grabsch, A.F. Why small-scale testing of reagents goes wrong. In Proceedings of the 18th International Seminar on Paste and Thickened Tailings, Perth, Australia, 5-7 May 2015; Jewell, R., Fourie, A.B., Eds.; Australian Centre for Geomechanics: Crawley, WA, Australia, 2015; pp. 153-165.

10. Dean, E.W.; Stark, D.D. A convenient method for the determination of water in petroleum and other organic emulsions. Ind. Eng. Chem. 1920, 12, 486-490. [CrossRef]

11. Kaminsky, H. Demystifying the methylene blue index. In Proceedings of the Fourth International Oil Sands Tailings Conference, Banff, AB, Canada, 7-10 December 2014.

12. Unified Fines Method for Minus 44 Micron Material and for Particle Size Distribution; COSIA Fines Measurement Working Group: Calgary, AB, Canada, 2015.

13. Sadighian, A.; Revington, A.; Kaminsky, H.; Moyls, B.; Li, Y.; Omotoso, O. A new protocol to assess the quality of tailings flocculation/coagulation: A collaboration to improve tailings treatment at Suncor Energy. In Proceedings of the Sixth International Oil Sands Tailings Conference, Edmonton, AB, Canada, 9-12 December 2018; pp. 81-92.

14. Vedoy, D.R.L.; Soares, J.B.P. Water-soluble polymers for oil sands tailings treatment: A review. Can. J. Chem. Eng. 2015, 93, 888-904. [CrossRef]

15. Demoz, A.; Mikula, R.J. Role of mixing energy in the flocculation of mature fine tailings. J. Environ. Eng. 2011, 138, 129-136. [CrossRef]

16. Revington, A.; Benito, M.; Kushagra, M. Automated Analyzer and Methods for Analysis of Tailings Samples Subjected to Flocculation. Canadian Patent 2981529, 29 March 2019.

17. Mikula, R.; Omotoso, O. Role of clays in controlling tailings behavior in oil sands processing. Clay Sci. 2006, 12 (Suppl. 2), 177-182.

18. Mikula, R. The role of clays in the performance of oil sands tailings management options. In Introduction to Oil Sands Clays; CMS Workshop Lectures; The Clay Minerals Society: Chantilly, VA, USA, 2018; Volume 22, pp. 129-182.

19. Yong, R.N.; Sethi, A.J. Method for Determining Clay Content in Tailings and Sludge. Canadian Patent 1,150,610A, 26 July 1983.

20. Sethi, A.J. Methylene blue test for clay activity determination in fine tails. MRRT Procedures, 23 January 1995.

21. Mikula, R.J.; Omotoso, O. Predicting oil sands tailings behavior from clay content and water chemistry. In Proceedings of the 2002 Canadian International Petroleum Conference, Calgary, AB, Canada, 11-13 June 2002; pp. 1-15.

22. Well, P.S.; Kaminsky, H. Slurry to soil clay behavior model-Using methylene blue to cross the process/geotechnical engineering divide. In Proceedings of the Tailings and Mine Waste, Vancouver, BC, Canada, 25-28 October 2015.

23. Dolinar, B.; Macuh, B. Determining the thickness of adsorbed water layers on the external surfaces of clay minerals based on the engineering properties of soils. App. Clay Sci. 2016, 123, 279-284. [CrossRef]

24. Hang, P.; Brindley, G. Methylene blue adsorption by clay minerals-Determination of surface areas and cation exchange capacities. Clay. Clay Miner. 1970, 18, 203-212. [CrossRef]

25. Vietti, A. Clay-Water interactions. In Introduction to Oil Sands Clays; CMS Workshop Lectures; The Clay Minerals Society: Chantilly, VA, USA, 2018; Volume 22, pp. 61-74. 